\title{
PRELIMINARY COMIMUNICATIONS
}

\section{Immunoreactive Insulin Content of 203 Pancreases from Foetuses of Healthy Mothers}

\author{
G. K. Rastogi, J. Letarte, and T. R. Fraser
}

Endocrine Unit, Department of Medicine, Royal Postgraduate Medical School, London W. 12, England

Received: December 18, 1969

\section{Introduction}

Insulin has been reported as extractable from the pancreas of human foetus from 10-12 weeks gestational age $[3,6]$, or about the period when islet cells can be clearly seen in sections [3, 5, 4]. But insulin synthesis has been reported to procede $\mathbf{B}$ granulation in the pancreas from human foetuses [3], as well as in those of rat, rabbit, mouse and hamster [2]. Also one report mentioned that insulin was demonstrable in the heart blood of a 12 week old human foetus [6]. As endogenous insulin secretion may play an important role in foetal growth, it seemed important to assess the pancreatic content of insulin at different gestational periods. But the available reports have dealt only with a few observations and have not assessed the pancreatic insulin content in relation to age. The present paper reports the immunoreactive insulin (IRI) content of 203 pancreases from human foetuses aged 11-27 weeks.

\section{Materials and Methods}

Fresh human foetal pancreases obtained after surgical termination of the pregnancy of healthy

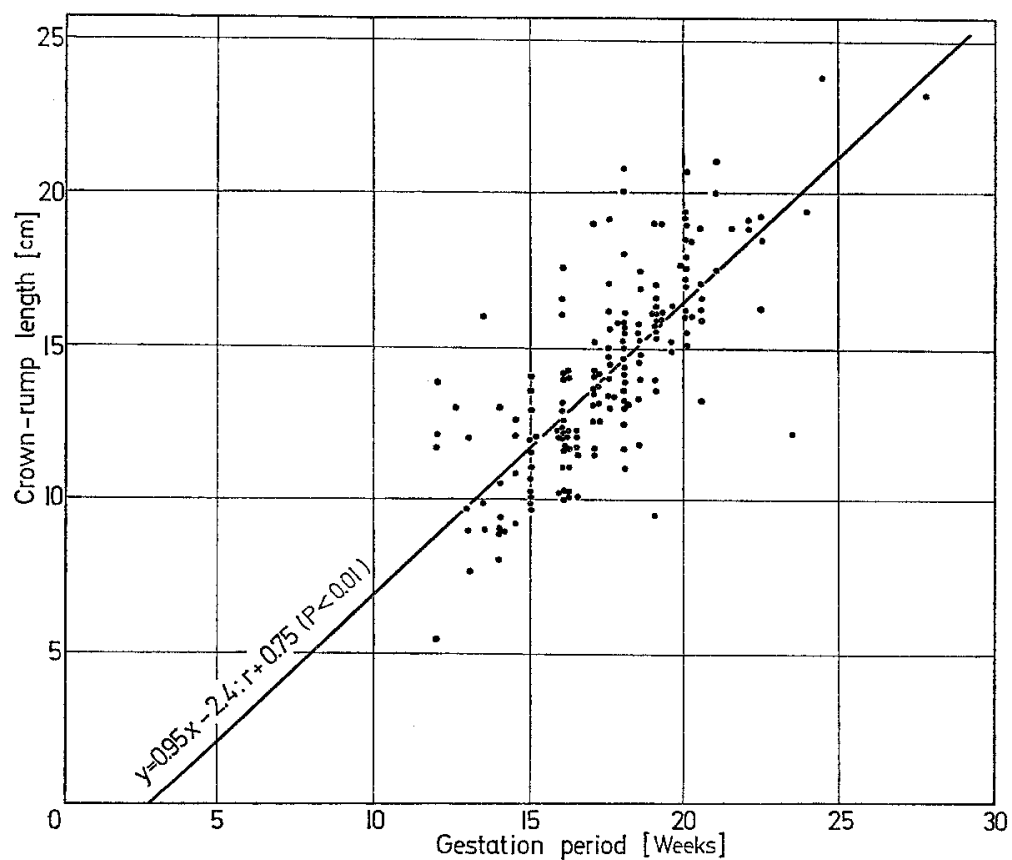

Fig. 1. Correlation between foetal erown rump length $(\mathrm{cm})$ and correct gestational age (weeks) as recorded by the mother mothers were kept at $-20^{\circ} \mathrm{C}$. For all the foetuses the crown-rump length (CR length) was recorded and also the correct gestational age when known.

Extraction was carried out with acid ethanol (ethanol:75, $\mathrm{H}_{2} \mathrm{O}: 25$, conc. $\mathrm{HCl}: 1.5 \mathrm{v} / \mathrm{v}$ ), $1.0 \mathrm{ml} / 50$ $\mathrm{mg}$ wet pancreas. The tissue was homogenized by a gun-type homogenizer, and left overnight at $4^{\circ} \mathrm{C}$ with gentle stirring; next morning it was centrifuged at $20000 \times g$ at $4^{\circ} \mathrm{C}$ for $60 \mathrm{~min}$; the supernatant was stored at $-20^{\circ} \mathrm{C}$ until assayed. Tracer ${ }^{125} \mathrm{I}$-insulin was used to estimate the recovery. The IRI was measured by a double-antibody technique [6] using human insulin standards and an antiserum against human insulin. The insulin content of pancreas was calculated as units/g wet weight.

\section{Results}

Precision. The recovery of ${ }^{125} \mathrm{I}$-insulin tracer in these pancreatic extractions was $88 \pm$ S.D. $3 \%$. Further, although the correct gestational age recorded by the mother was not always forthcoming, the alternative but more objective foetal $\mathrm{CR}$ length was used as the main index of foetal age. Fig. 1 shows that this CR length correlated well with the gestational age in weeks when recorded by the mother.

Relation to age. Fig. 2 shows the IRI content of 203 foetal pancreases in relation to the foetal CR length. IRI was demonstrable in all the pancreases from the youngest foetus tested, i. e. $8-9 \mathrm{~cm} \mathrm{CR}$ length equivalent to 11-12 weeks gestational age. The average pancreatic insulin content was 2 units/g at $8-10 \mathrm{~cm} \mathrm{CR}$ length, or 11-13 weeks, and progressively increased to 6 units $/ g$ at $19 \mathrm{~cm}$ CR length, or 23-24 weeks. The foetuses beyond 24 weeks were too few, but their values up to 27 weeks did not suggest any further rise.

Comparison with adults. The righthand corner of Fig. 2 shows the IRI content (mean \pm S.E.) found in four adult human pancreases, which were extracted and assayed similarly. Here values may have been lower because delay in postmortem deep freezing was several hours $(4-48 \mathrm{~h}$ ) longer, and furthermore proteolytic enzymes would have been available. 


\section{Discussion}

The present results confirm that insulin is extractable from human foetal pancreas from at least 11-12 weeks gestational age. The progressive rise in the mean insulin content from 2 units/g at $11-13$ weeks to 6 units/g at 23--24 weeks suggests that steadily increasing quantities of insulin become available over 11 th to 24 th weeks possibly for promoting foetal growth. Moreoever, this large number of pancreases has defined the mean pancreatic insulin content at different foetal ages during the first half of human gestation. This data should enable assessment of the contribution of insulin secretion to foetal mortality. until a further rise in the pancreatic insulin content towards term concomitant with the increasing growth of the secondary islets.

Our results suggest a higher pancreatic insulin content in foetal life. Wrenshall et al. [9] had reported similarly for early post-natal life. Evidently islet cells constitute a greater proportion of pancreatic weight in these periods than in later life, when demands for acinar secretion alter the balance.

Acknowledgemenis. We gratefully acknowledge the generous help of Dr. H. E. M. Key of the Royal Marsden Hospital, London, who kindly supplied us with the pancreases.

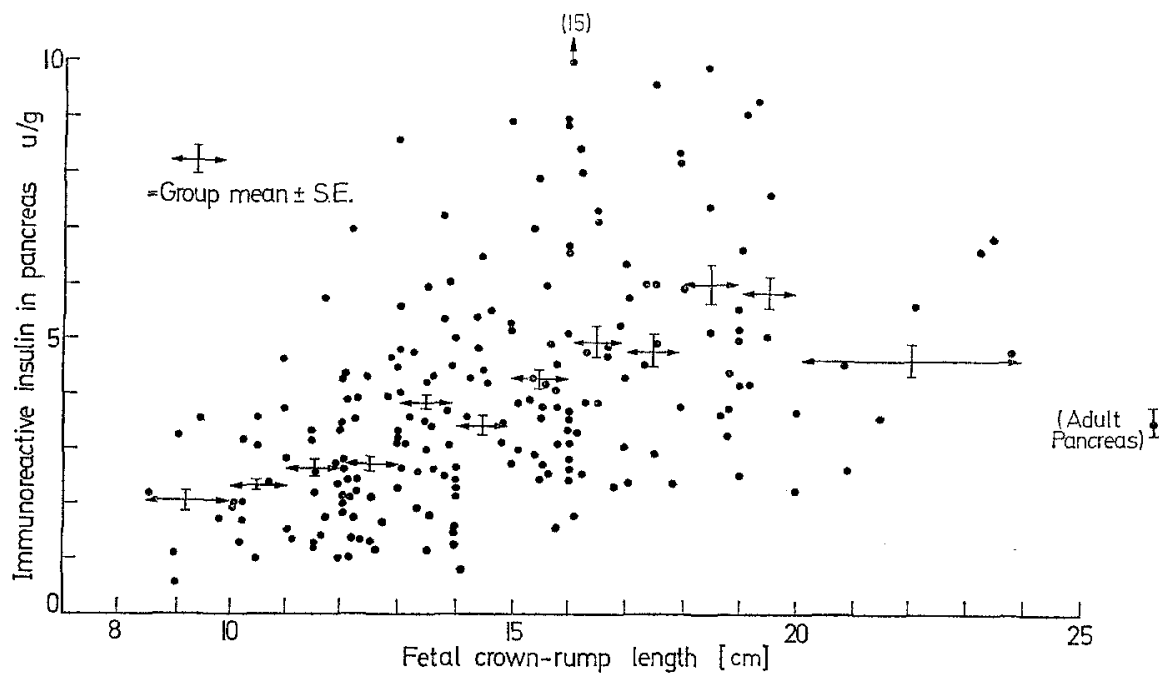

Fig. 2. Foetal pancreatic insulin (units/g wet weight) in relation to the age of the foetus as indexed by the foetal erown-rump length. The horizontal bars represent the mean value of the group and vertical bars the S.E.M.

Maternal diabetes and prediabetes are associated with foetal loss and also with foetal pancreatic islet cell hyperplasia and hyperinsulinism $[6,8,1]$.

Our finding of 6 units/g pancreatic insulin content at 23-24 weeks agrees with Steinke \& Driscoll's [6] report of finding a mean concentration of 6.3 units $/ \mathrm{g}$ in 20-32 week old foetuses. These authors also reported that in older foetuses ( 34 weeks to term) the mean insulin content was higher at 12.7 units/g. From a study of 130 pancreases from human embryos and foetuses, Liu and Potter [4] have reported that two generations of islands appear during pancreatic development. The primary crop originates from primitive pancreatic ducts at 8 weeks gestation, reach maturity in the fifth month and degenerate thereafter. The secondary islands grow from the cells of the terminal ducts in the third month of foetal life, continue to increase in size and number during the rest of the foetal life, and constitute the permanent islands. Both our results and those of Steinke and Driscoll's [6] tend to corroborate Liu and Potter's [4] observations. Thus there is first a progressive increase in pancreatic insulin content up to the fifth month when it plateaus,

\section{References}

1. Billis, A., Rastogi, G.K.: Studies in methods of investigating carbohydrate tolerance during pregnancy. Diabetologia 2, 169-177 (1966).

2. Grillo, T.A.I.: The occurrence of insulin in the pancreas of some rodents. J. Endocr. 31, 67-73 (1964).

3. - Shima, K.: Insulin content and enzyme histochemistry of human foetal pancreatic islets. J. Endocr. 36, $151-158(1966)$.

4. Liu, H.M., Potter, E.L.: Development of the human pancreas. Arch. Path. 74, 439-452 (1962).

5. Robb, P.: The development of the islets of Langerhans in the human foetus. Quart. J. exp. Physiol. 46, 335343 (1961).

6. Steinke, J., Driscoll, S. G.: The extractable insulin content of pancreas from foetuses and infants of diabetic and control mothers. Diabetes 14, 573-578 (1965).

7. Welborn, T.A., Fraser, T.R.: The double antibody immunoassay of insulin. A standardized second antibody reaction that eliminates spurious results with human serum. Diabetologia 1, 211-218 (1965).

9. Wrenshall, G. A., Bogoch, A., Richie, R.C.: Extractable insulin of pancreas. Diabetes 1, 87-107 (1952).

Dr. G.E. Rastogi

Department of Medicine

Postgraduate Medical Institute

Chandigarh, India 